\title{
Du coton traditionnel au coton colonial, le coup de force du progrès (Nord-Cameroun)
}

From traditional to colonial cotton: the coup de force of progress in North

Cameroon

\section{Christian Seignobos}

\section{(2) OpenEdition}

\section{Journals}

Édition électronique

URL : http://journals.openedition.org/ethnoecologie/4067

DOI : $10.4000 /$ ethnoecologie.4067

ISSN : 2267-2419

Éditeur

Laboratoire Eco-anthropologie et Ethnobiologie

Référence électronique

Christian Seignobos, "Du coton traditionnel au coton colonial, le coup de force du progrès (NordCameroun) », Revue d'ethnoécologie [En ligne], 15 | 2019, mis en ligne le 30 juin 2019, consulté le 29 octobre 2019. URL : http://journals.openedition.org/ethnoecologie/4067 ; DOI : 10.4000/ ethnoecologie. 4067

Ce document a été généré automatiquement le 29 octobre 2019

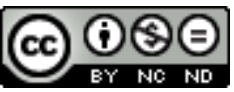

Revue d'ethnoécologie est mis à disposition selon les termes de la licence Creative Commons Attribution - Pas d'Utilisation Commerciale - Pas de Modification 4.0 International. 


\section{Du coton traditionnel au coton colonial, le coup de force du progrès (Nord-Cameroun)}

From traditional to colonial cotton: the coup de force of progress in North

Cameroon

Christian Seignobos

\section{Introduction}

1 Le coton était présent tout au long de mes séjours dans le nord du Cameroun (Figure 1) sans qu'il ne devienne pour moi un réel sujet d'étude, même si j'ai initié avec Jacques Schwendiman (CIRAD), à la fin des années 1980, une prospection des cotonniers pérennes, dits "traditionnels", sur l'ensemble du pays, qui a contribué à la création d'un arboretum à l'Institut de Recherche Agronomique de Maroua. Ces cotonniers étaient souvent présents dans et près des habitations qui faisaient l'objet de mes travaux sur les architectures traditionnelles. Dans ces mêmes lieux, les dernières activités de tissage ne pouvaient que retenir mon attention. Les levés et études de terroirs villageois dans divers exercices de géographie rurale intégraient le plus souvent une sole cotonnière. 
Figure 1 : Carte de situation

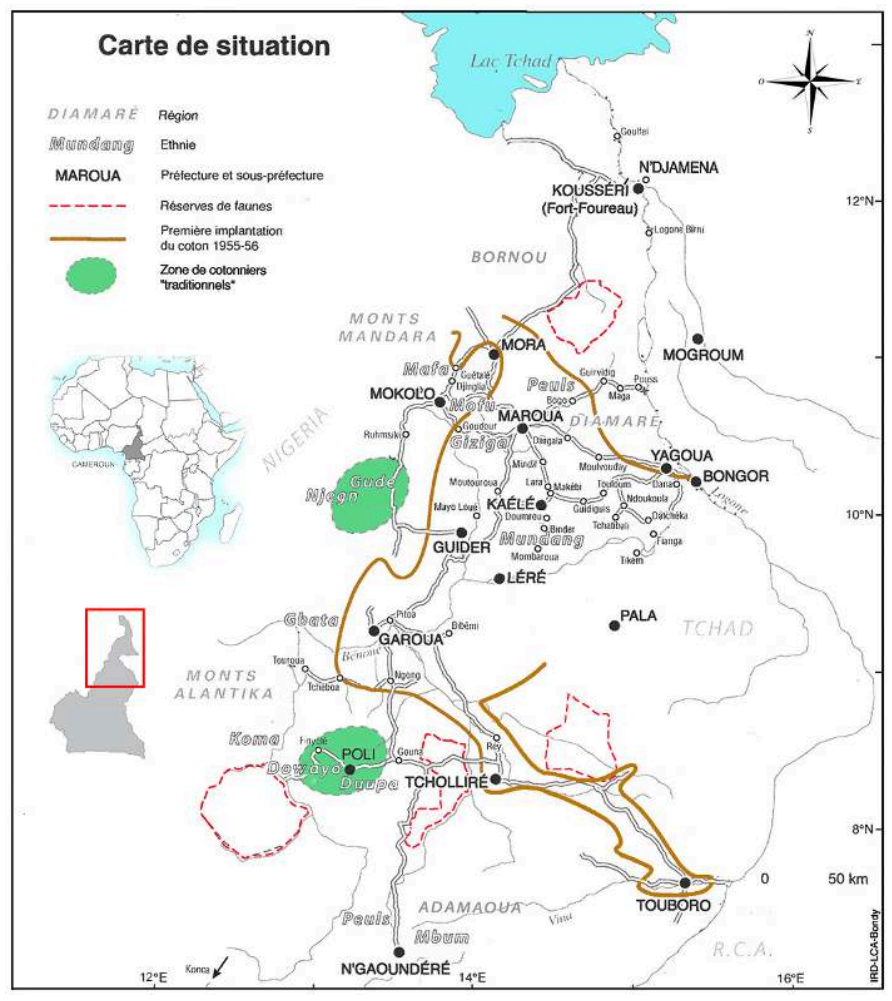

2 J'avais, par ailleurs, mené des enquêtes intéressant la période de pré-indépendance, à partir d'archives et auprès d'acteurs privilégiés de cette époque, les interprètes coloniaux, dont l'une concernait l'arrivée du coton industriel.

Dans une première partie je reprends mes notes sur le passé cotonnier du nord du Cameroun et enchaîne, dans une seconde, sur une analyse qui se veut détaillée sur l'imposition du « coton colonial ».

4 La situation est singulière, le « coton colonial » intervient ici dans la région du Nord Cameroun tardivement plus de 20 ans après le Tchad voisin. Cette spéculation va devoir être imposée dans des zones où se cultivent encore des cotonniers arbrisseaux traditionnels dont la production a alimenté, depuis la seconde moitié du XIX ${ }^{e}$ siècle, un complexe d'artisanats et des échanges très actifs, pour l'essentiel dans les principautés musulmanes.

\section{Le coton indigène, état des lieux avant 1950}

5 Jusque dans les années 1940, on retrouve dans les archives coloniales du Cameroun des listes de noms de cotonniers, toujours en fulfulde, la langue peule. Parmi les cotonniers locaux sont mentionnés le foulfouo (ou foulfoulo, foulfoullo) et le woulgo des Peuls du Diamaré, le kontchao et le mboumo pour l'Adamaoua, le tchario du pays mandara. C. Kieffer (1931: 5), conducteur de travaux d'agriculture, signale que, parmi ces variétés, Gossypium arboreum, G. punctatum et une variété hybridée dominent. Il rajoute également :

« les cotonniers indigènes ont évolué différemment. Chez les kirdi [païens] (Guiziga

et montagnards) on parle d'ottolo manga (G. arboreum), un grand cotonnier de 1,5 à

$2 \mathrm{~m}$ qui peut parfois dépasser les $6 \mathrm{~cm}$ de diamètre; alors qu'en plaine domine l' 
otollo foulbé (G. hirsutum), petit cotonnier de $1 \mathrm{~m}$. de hauteur, au port nettement étalé et à nombreuses ramifications ".

\section{Variétés locales et façons culturales}

6 Les classifications, parfois confuses, des données coloniales ont pu être clarifiées au cours d'une mission en novembre et décembre 1988 (Seignobos \& Schwendiman 1991). Nous avons pu observer ces cotonniers traditionnels dans des espaces non couverts par la Sodecoton ${ }^{1}$. Lorsque fut envisagé, dans les années 1950, la culture annuelle du cotonnier Allen $^{2}$, ordre fut donné d'éradiquer les cotonniers arbrisseaux locaux. Une crainte se mue en credo: les cotonniers pérennes vont entretenir des insectes ravageurs et constituer des réservoirs de maladies pour la culture que l'on cherche à promouvoir. Nous avons dû alors prospecter des régions reculées, de montagne, ayant de surcroît refusé le coton colonial, comme les pays njegn et gude dans les monts Mandara et la région de Poli au sud de la Bénoué. Cette présence relictuelle, pourtant abondante dans certains sites, nous a permis d'observer des formes originales de cotonniers arborescents, voire lianescents, ayant besoin de support ou profitant des haies d'euphorbes en pays duupa-dowayo ou encore des cotonniers à fibres teintées en brun, ocre et oranger réservées aux broderies chez les Njegn.

7 Gossypium arboreum race soudanense, serait le li'eere sa'ta biye (cotonnier/dure/graine) appelé encore sataho ou li'eere wuluuko ${ }^{3}$ (cotonnier / Pennisetum pedicelatum, nom d'une grande graminée que l'on retrouve partout) (Tourneux \& Seignobos 1997: 206). Il présente deux phénotypes, l'un à feuille verte, l'autre à feuille pourpre, la pigmentation anthocyanique ${ }^{4}$ pouvant toucher l'ensemble de la plante. Il est plutôt cultivé près et dans les habitations. Venant de l'est, vraisemblablement à travers les royaumes musulmans, sa présence est la plus ancienne (Figure 2). 


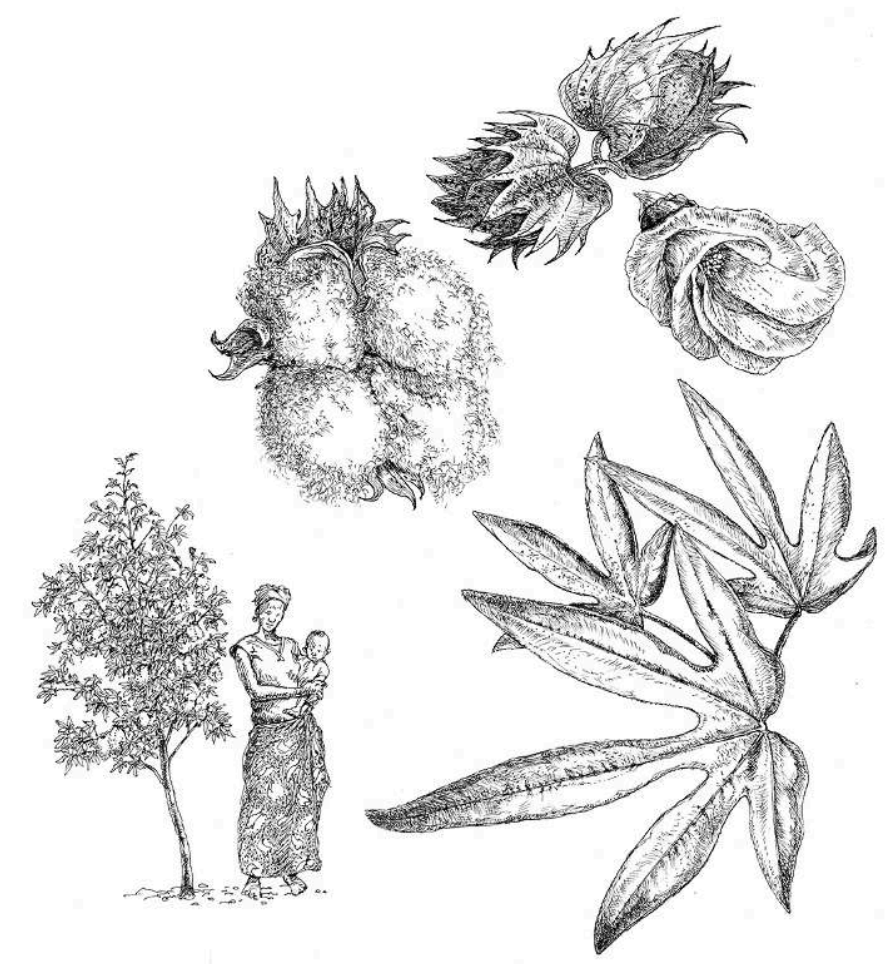

Inflorescence avec calice et fleur (haut, droite), fruit (haut, gauche), feuilles (bas, droite) et arbrisseau (bas, gauche)

Dessin C. Seignobos

Gossypium hirsutum race punctatum correspond le plus souvent à li'eere fulfulho (« notre cotonnier » par opposition aux cotonniers des non Peuls). Précoce, exprimant peu de variations morphologiques il est cultivé en champ. Il est originaire de l'ouest, du nouveau monde via la côte, depuis l'époque de la traite $\left(\mathrm{XVII} \mathrm{e}^{\mathrm{e}}\right)$. Confondu avec lui, mais d'introduction plus récente (fin $\mathrm{XIX}^{\mathrm{e}}$ ?), Gossypium hirsutum race latifolium, de type Upland, serait une sorte d'ancêtre des variétés commerciales actuelles ${ }^{5}$.

Li'eere koncaho, originaire d'un lamidat ${ }^{6}$ méridional, celui de Konca est le Gossypium barbadense, également originaire des Amériques, remonté directement de la côte dans la seconde partie du xix ${ }^{\mathrm{e}}$ siècle. Quant à Gossypium barbadense variété brasiliense, aux graines « rognons » soudées au sein d'une loge, il n'aurait fait son apparition que vers les années 1925-1930.

10 Au cours de nos prospections, Gossypium herbaceum race acerifolium, identifié par ses feuilles pentalobées larges et ramassées, et la pilosité de ses tiges et de ses feuilles, n'a été rencontré que dans la région de Poli. Encore bien représenté au début de la période coloniale il a subi un délaissement inexpliqué (Seignobos \& Schwendiman 1991).

Des cotonniers nouveaux n'ont cessé de se diffuser dans la région, apportés par les essais agronomiques coloniaux. On les appelle alors hottollo, désignant au départ la fibre ouatée du coton et qui, par un glissement de sens, devient le coton administratif, celui de la culture de rente. Parmi ces hottollo nasaara (coton du blanc), on relève un hottollo paskale - du nom d'un célèbre agent d'agriculture, Pascalet et un cotonnier venu du Tchad, baptisé hottollo manakace ${ }^{7}$ du nom du chef de Subdivision de Léré au Tchad, Manicacci (1929-1931), qui l'a imposé. Avant les années 1950, apparaît un cotonnier 
annuel, sans doute venu du Nigeria, sous le nom de hottollo madam. Tous seront réinterprétés en pluriannuels, intégrés et semés dans les lignes de cotonniers traditionnels.

Les cotonniers pérennes étaient cultivés sur de petites parcelles généralement derrière les concessions comme actuellement chez les Dowayo, ou en complantage avec des sorghos et d'autres cultures, et aussi sur de vastes champs, comme à Binder. La région de Binder, au Tchad à la frontière du Cameroun, représente une région cotonnière particulière à la suite de l'intérêt porté par les princes (lamibe) eux-mêmes à cette culture. Ils surveillaient de bout en bout la culture du coton, la disposition des plants de 60 à $80 \mathrm{~cm}$-, le moment des récoltes (Figure 3) - d'octobre à décembre -, mais aussi l'écartement des dents des peignes des métiers, le poids du chariot pour obtenir des tissus au grain le plus fin possible. C'était la seule région où l'on rencontrait trois types de métiers à tisser (Lamb \& Lamb 1981). Sa production d'étoffes réputées faisait l'objet d'un important trafic dans tout l'Adamawa.

Ailleurs les disciplines agraires semblaient moins rigoureuses. G. arboreum, taillé plutôt en têtard, était remplacé tous les sept à huit ans; G. hirsutum était recépé au-dessus du plateau de racines tous les deux ans et on les arrachait après le troisième recépage. Telles qu'observées dans les années 1930, ces cultures manqueraient de soins. Selon C. Kieffer $(1931: 6)$

« les semis sont faits en poquets, sans aucune méthode et sans tenir compte d'aucun espacement. Souvent, les opérations de démariage et d'écimage ne sont pas faites, bien moins encore les façons culturales en cours de végétation ».

Figure 3 : Le lamido de Binder, Haalidu Mal Dawda, vers 1900, surveillant ses champs de cotonniers (Gossypium herbaceum)

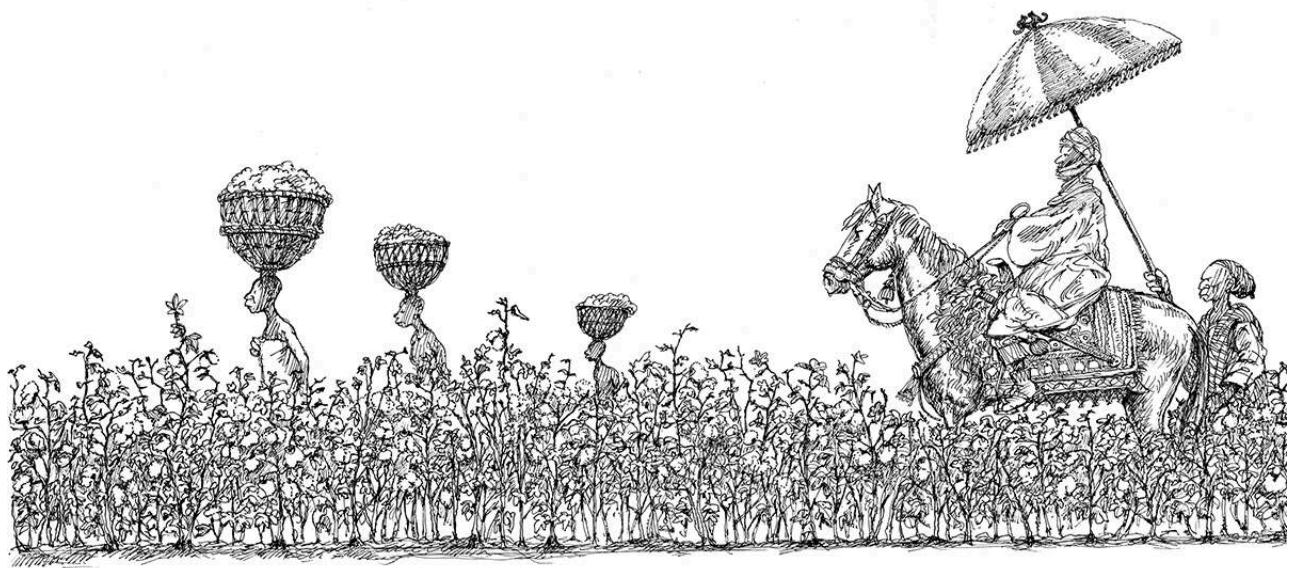

Dessin C. Seignobos

\section{L'âge d'or des tisserands et des foulons}

Le cotonnier s'est initialement développé dans les royaumes musulmans du circum tchadien. L'islam prohibe fortement la nudité corporelle, aussi l'islamisation des populations s'est partout accompagnée de la diffusion du tissu de coton, de sa culture et de l'artisanat qui y est attaché. Il participe à l'activité commerciale comme élément 
possible de substitution à la seule unité de valeur, l'esclave (Shimada 1992). Les bandes de tissu, appelées en fulfulde leppol (pl. leppi), mais plus généralement gabak (gabaga), en kanuri, sont des bandes de 4,5 à $10 \mathrm{~cm}$ de largeur, tissées sur des métiers horizontaux à pédales. Elles sont cousues bord à bord pour en faire des vêtements. Les couseurs de bandes de gabak constituaient souvent une branche à part de cet artisanat. Mesurées à la coudée - la mesure la plus courante étant de deux coudées et demie - elles représentaient une forme d'étalon monétaire commode. Elles pouvaient être conditionnées en rouleaux de plus d'un mètre de diamètre et susceptibles d'être ainsi capitalisées. Cette monnaie d'étoffe de gabak avait cours depuis le $\mathrm{XIV}^{\mathrm{e}} \mathrm{ou} \mathrm{XV} \mathrm{V}^{\mathrm{e}}$ siècles au Bornou (Lamb \& Lamb 1981). Les filés de ces cotonniers arbrisseaux semblent avoir été utilisés de façon indifférenciée pour tisser les mêmes bandes de gabak, excepté peutêtre à Binder et à Maroua.

Le royaume du Bornou fut le grand initiateur de toutes les techniques artisanales dans le bassin du lac Tchad. Ce sont les Bornouans ou Kanuri, encore appelés Sirata dans le nord du Cameroun, qui ont introduit les variétés de cotonniers G. arboreum et $G$. herbaceum, puis $G$. hirsutum jusque dans les centres de pouvoirs païens forts, comme les pays gude, gbata, mundang. À partir de là, la culture du coton gagnera des aires de peuplement plus enclavées, des Gbata vers les Dowayo et les Fali, par exemple. La vulgarisation du coton sera assurée dans l'Adamaoua peul, lorsque les différentes principautés auront créé dès avant le milieu du xix siècle un maillage en continu à travers les plaines et espaces ouverts, puis elle passera ensuite chez les populations tributaires.

Dès la seconde moitié du XIX ${ }^{e}$ siècle, dans les principautés musulmanes, des équipes mobiles de tisserands bornouans se déplaçaient avec leurs métiers horizontaux à pédales, de village en village pendant la saison sèche (Figures 4 et 5) Les pièces mobiles du métier, le peigne - base en bois de caïlcédrat (Khaya senegalensis) ou de bouleau d'Afrique (Anogeissus leiocarpus) et dents en fer -, les lisses et la poulie (l'ensemble pesant de 0,7 à $0,9 \mathrm{~kg}$ ) étaient susceptibles d'être retirées à tout moment (Figure 6). Le tisserand, potentiellement ambulant, pouvait se déplacer jusqu'aux marges des principautés musulmanes, créant auprès des groupes païens périphériques une demande en coton filé. Les hommes ont filé avant de tisser. Puis les femmes ont assuré le filage. Les Hausa, plus tard et plus au sud, devaient assurer cette même diffusion du coton et du tissage (Lamb \& Lamb 1981). Des places leur étaient réservées auprès des chefs ou sur des marchés (sannirde). Ils tissaient le coton des paysans locaux, gardant en paiement une partie des rouleaux de gabak qu'ils avaient réalisés sur place. Ils distribuaient également des semences de coton et prodiguaient des conseils pour leur culture. Cela existait encore dans les années 1940 chez les Kotoko. Toutefois les Bornouans étaient plus identifiés encore par leurs compétences dans la teinture des tissus et le terme de foulon ('balinoowo) était devenu synonyme de Kanuri ${ }^{8}$. Les Bornouans aménageaient, près des marchés, des bacs à teinture, cuves maçonnées, (waawru) que l'on refermait d'un opercule durant la saison des pluies et des cultures. De la même façon qu'ils avaient diffusé les graines de cotonniers, ils le firent avec des variétés d'indigotiers, Indigofera tinctoria (cacaari). Ainsi, tout au long des routes caravanières partant du Bornou vers le sud, de part et d'autre des monts Mandara, les différents groupements païens cultivaient du coton pour fournir des filés ainsi que des boules d'indigo aux commerçants bornouans ambulants. D'autres couleurs devaient être développées avec la culture de Sorghum caudatum var. colorans pour le rouge, grâce 
à leurs cannes anthocyanées et les broderies à partir de certaines soies (saamiya), principalement celle sécrétée par la chenille du lépidoptère Anaphe infracta, inféodé au tamarinier (Tamarindus indica).

Figure 4 : Un métier à tisser horizontal, à pédales (Tchadic du Nord), chez les Giziga, village de Mogoudi (1984), voir également Lamb \& Lamb (1981)

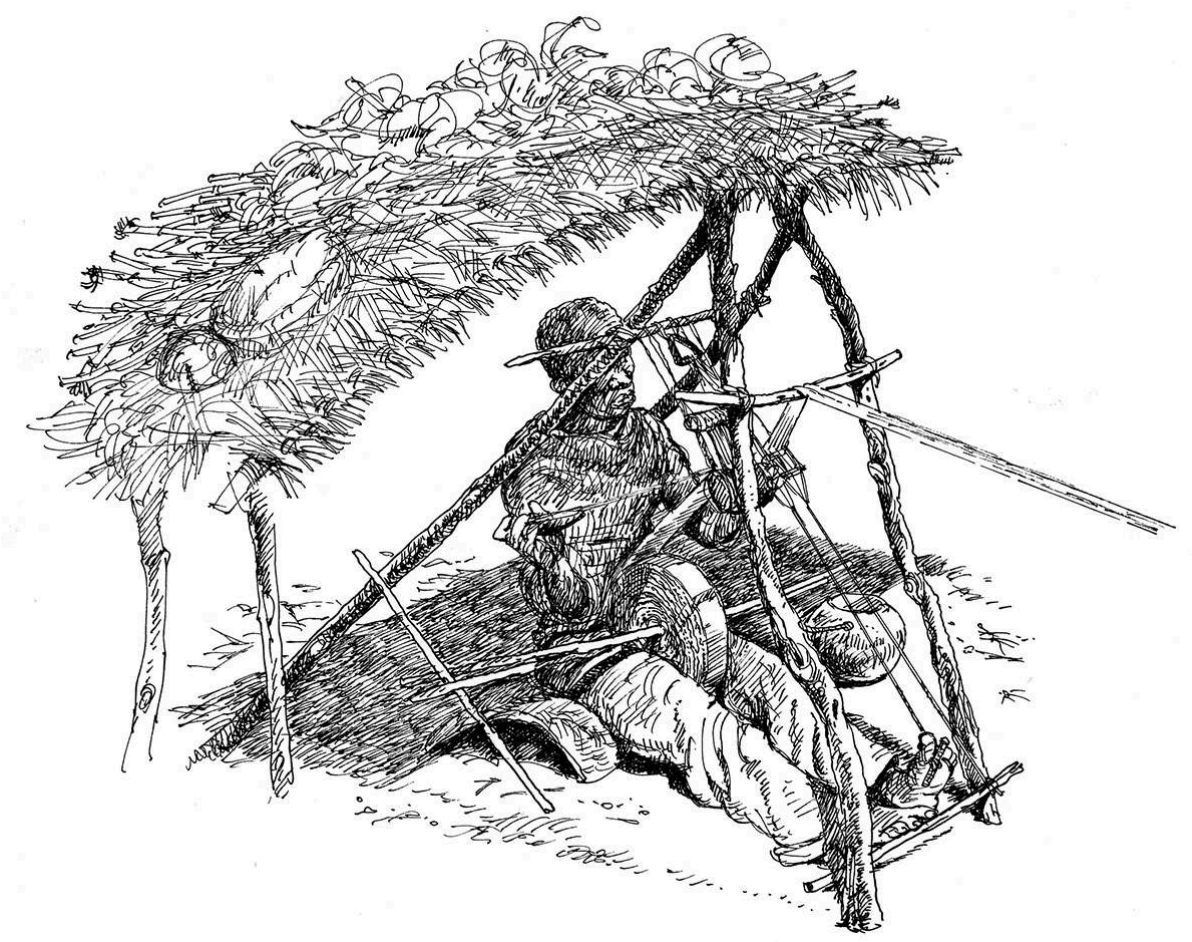

Dessin C. Seignobos 
Figure 5 : Haut gauche et bas droit : Un métier à tisser au repos chez les Gidar, village de Kongkong (1986). Bas, gauche : Schéma de fonctionnement d'un métier horizontal à pédales

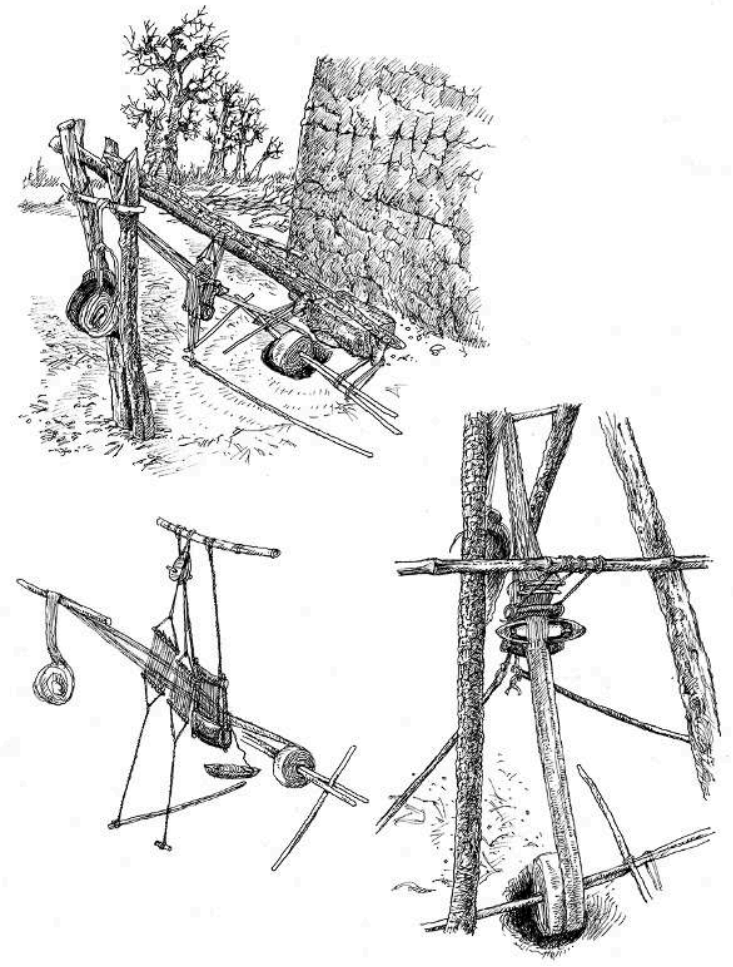

Dessin C. Seignobos 
Figure 6 : Ensemble des pièces mobiles du métier à tisser " Tchadic » : le peigne, les lisses, la poulie et l'amorce de la chaîne

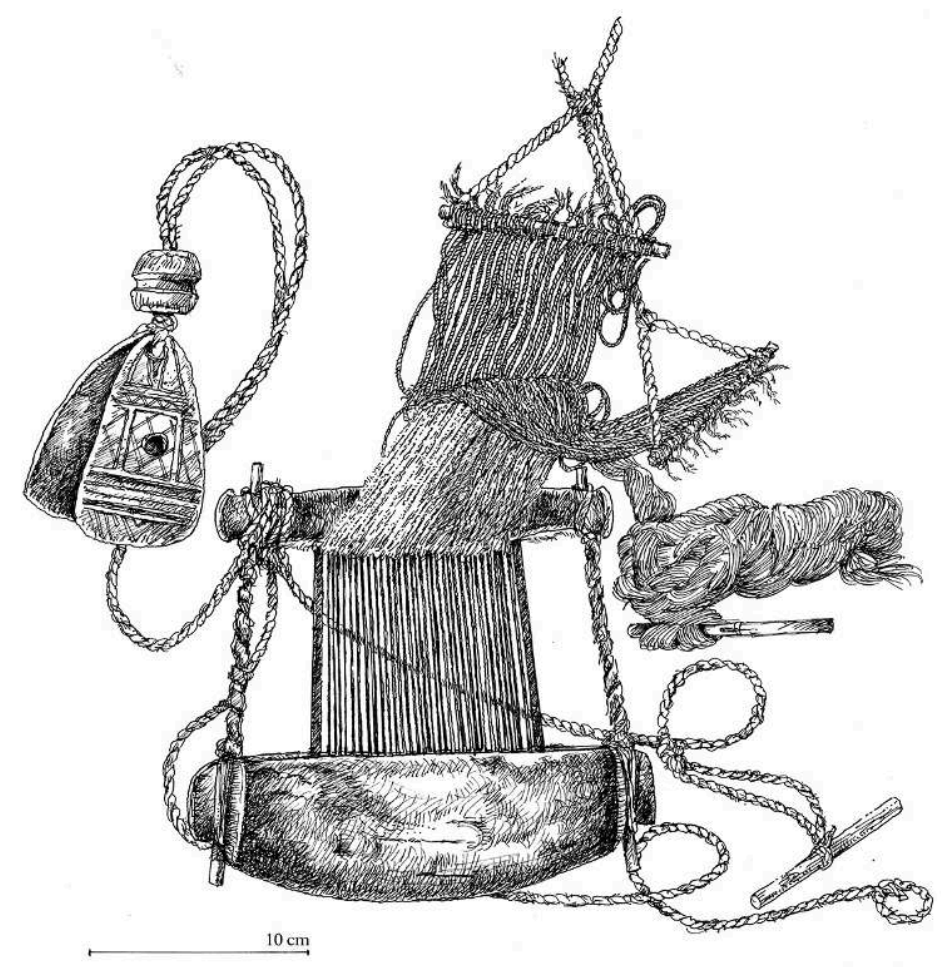

Dessin C. Seignobos

L'adoption de la culture des cotonniers pérennes s'est faite progressivement. On cultive et file d'abord le coton, que l'on peut observer sur de nombreux sites de villages jonchés de fusaïoles de terre cuite, sphériques, cylindriques, tronconiques aux bords lisses ou dentelés, (Figure 7). Les filés de coton s'échangent avec les commerçants, affranchis des principautés peules contre des perles et des barrettes de métal. Les filés de coton entrent dans les compensations matrimoniales et se maintiendront longtemps, comme chez les Fali, encore au début du $\mathrm{xx}^{\mathrm{e}}$ siècle pour ouvrir des dots : un fuseau de filé de coton de $60 \mathrm{~cm}$ de long sur 20 de large. 


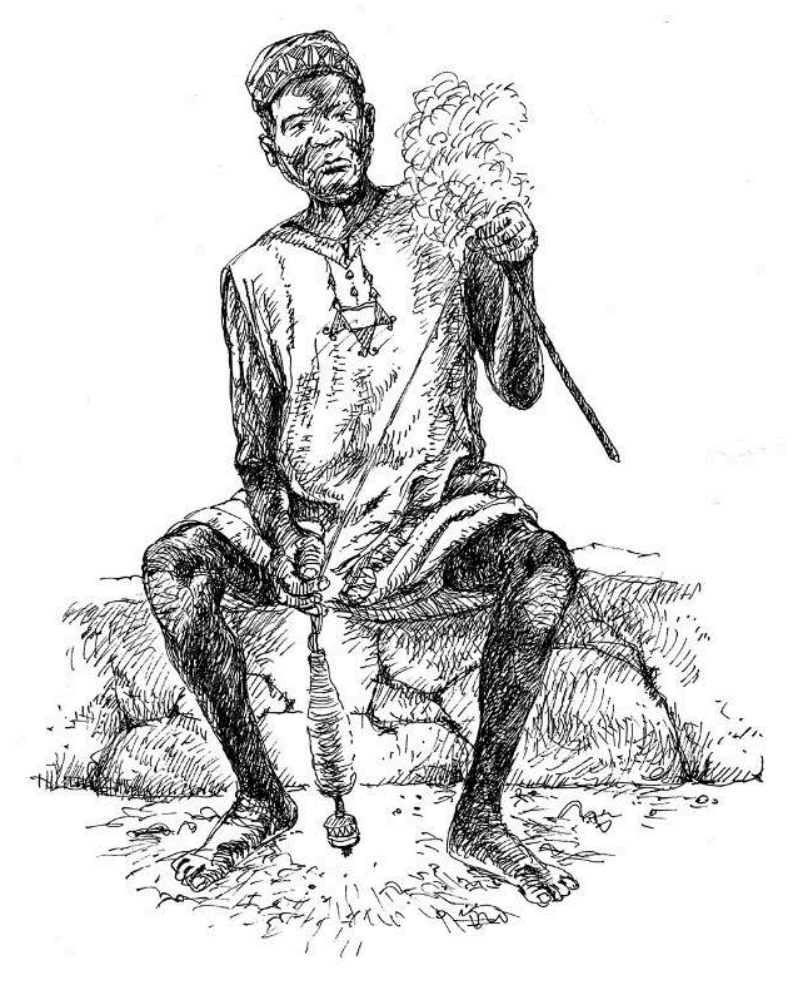

Dessin C. Seignobos

Chez les populations non musulmanes on habillera d'abord les morts. On rajoutera aux emballages de peau de bovins et de caprins des bandes de gabak, puis des vêtements, des gandouras, alors que ceux qui accompagnent l'enterrement n'en portent pas. Les groupes païens (Giziga, Mundang, Gidar...) les plus en contact avec des communautés musulmanes vont, sur leur copie, abandonner les emballages de peau pour un suaire de coton, qui deviendra rapidement une unité monétaire. Le suaire (zana) le plus prisé chez les Giziga sera le godon fabriqué par les femmes peules sur leurs métiers à tisser verticaux.

19 La paix coloniale, en établissant la libre circulation des personnes et en ouvrant les premiers marchés dans les pays haabe (païens), va entraîner un besoin de se vêtir, donc de cultiver cotonniers et indigotiers. Jusque vers 1935, un certain nombre de "groupements indigènes " pourront se "libérer » de l'impôt de capitation grâce au gabak $^{9}$. Les derniers groupes haabe vont alors - à l'exception de ceux des monts Mandara septentrionaux et des riverains du Logone - se mettre à la culture du coton ${ }^{10}$.

Depuis les monts Mandara septentrionaux jusqu'en pays dii, on pouvait rencontrer des groupements haabe occupant une grande partie de la saison sèche à filer pour les femmes et à tisser pour les hommes. Parmi ces tisserands compulsifs on remarquait les Dowayo où il n'existait pas un enclos sans métier à tisser horizontal à pédales, encore dans les années 1980. Ils fabriquaient aussi des cotonnades à gros fils, larges de 20 à $60 \mathrm{~cm}$ sur 7 à $12 \mathrm{~m}$. de longueur, avec alternance de couleurs : bleu, noir, rouge, mauve, tissées ici sur des métiers de fond. Ces hiile - appelés tapis dans le français local productions somptuaires, accompagnaient les dots et les funérailles. On retrouvera partout ces mêmes sayons de gabak ouverts sur les côtés ('danjiki), accompagnés de braies courtes (sirla ou ndoppa) également en gabak écru ou teinté, ainsi que le même 
bonnet (saayiire) la pointe rabattue sur le côté ou à l'avant et contenant tabac, briquet de fer et premières pièces de monnaie (Figure 8). Le « kit kirdi » a perduré jusque dans les années 1970 pour les villages les plus reculés. Chaque homme venait sur le marché portant son arc et un carquois d'apparat agrémenté de gabak, le couteau à la taille, le fourreau serré dans des bandes croisées de ce même gabak. Les Koma des monts Alantika, quant à eux, continuaient à se vêtir à l'ancienne jusque vers les années 1980, d'un tablier de gabak (benteere) sur le devant et un second, plus enveloppant, sur les reins, tendant à mordre sur le premier, l'ensemble fait de bandes alternées écrues ou teintées d'indigo clair ou foncé, mêlant parfois d'autres couleurs agrémentées de broderies (Figure 9).

Figure 8 : Exemples de vêtements confectionnés avec le coton traditionnel

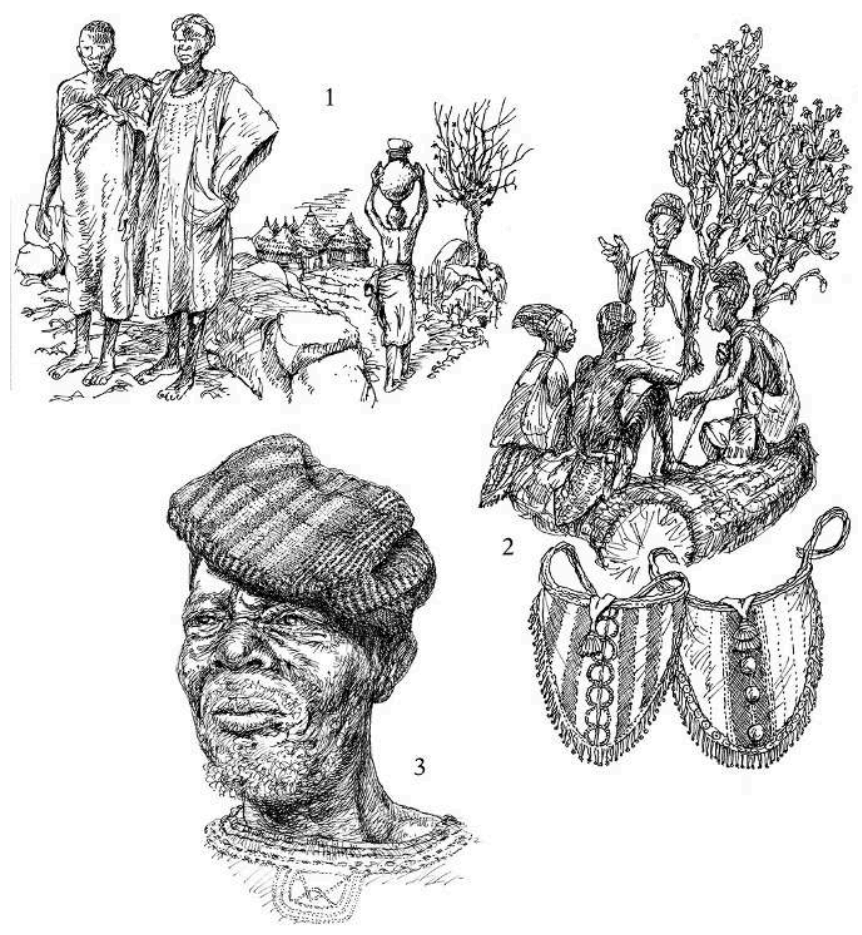

1- Pièces vestimentaires en godon (Mofu), benteere ; 2- Tablier double (Fali, Dowayo) ; 3- Saayiire, bonnet

Dessin C. Seignobos 


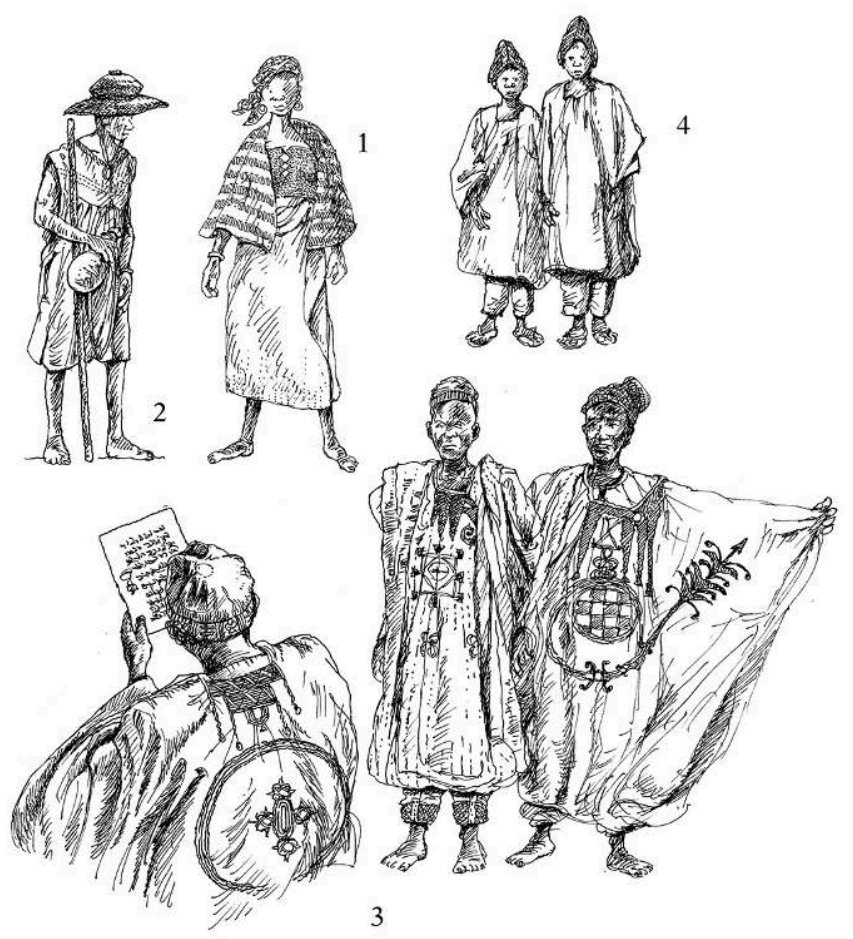

1- De la femme peule, adikko (mouchoir de tête), mojaare (châle), riga (bustier), wurre (pagne) ; 2Vêtements masculins : danjikiire (tunique d'éleveur) ; 3- Leppiwol ou janngaande (gandoura en bande de gabak), gaarewol (grand boubou brodé) ; 4- Lupaare (bonnet recouvrant les oreilles)

Dessin C. Seignobos

21 Cette évolution endogène d'un artisanat de villages foisonnant allait pourtant irrémédiablement s'éteindre sous le coup de l'arrivée du nouveau coton et sans doute plus encore de l'argent du coton qui fonctionna comme un accélérateur de changements déjà à l'œuvre.

\section{Promotion, puis abandon des variétés locales de cotonniers}

À Pitoa, en 1912 et 1913, un agronome allemand, le Dr. Wolf, avait entrepris une série d'essais sur les cotonniers locaux. Le Capitaine J. Lemoine, 1918, dans « Les pays conquis du Cameroun Nord » (texte dactyl. Archives ISH), signale page 99 :

«À une quinzaine de kilomètres de Garoua, dans un épanouissement de la plaine de la Bénoué, se trouve une station cotonnière [...]. Il ne reste actuellement que les plantations et défrichements, les bâtiments ayant été incendiés. Il semble que les Allemands avaient essayé un grand nombre de graines, car on retrouve des plants indigènes, plants à graines nues du Togo, du Dahomey, du Sea Island etc. ».

On pense, encore dans les années 1930, pouvoir tabler sur des variétés cotonnières locales dont on vante les qualités de fibres et dont on imagine pouvoir augmenter les rendements: "Dans la Région Nord, les indigènes cultivent surtout une variété dite foulfoulo qui a des qualités appréciables: sa fibre est bonne, elle résiste mieux aux maladies, n'est que très peu attaquée par les insectes et donne des rendements satisfaisants (jusqu'à 200 kilos de fibres à l'hectare dans le nord et 300 kilos à Foumban). Les autres variétés locales woulgo et kontchao produisent des fibres de bonne qualité, 
mais leur rendement est inférieur au coton foulbé (fulfulho). D'expériences faites à Garoua, il résulte que par une sélection opérée pendant plusieurs années consécutives on pourrait améliorer considérablement les cotonniers indigènes et obtenir des variétés très intéressantes " (Heim de Balzac 1930: 6). Pour d'autres qui, à la même époque, penchent pour la culture de cotonniers annuels exogènes, les rendements des variétés locales seraient de 100 à $150 \mathrm{~kg} / \mathrm{ha}$ et les variétés étrangères de $200 \mathrm{~kg} / \mathrm{ha}$ (Kieffer 1931 : 7). Quoiqu'il en soit, cette voie restera sans suite.

Déjà R. Pascalet, conducteur des travaux d'agriculture, ancêtre des ingénieurs agronomes, à Garoua (1927-1928), cherchera progressivement à promouvoir les cotonniers annuels au détriment des variétés locales. Pour lui, comme pour la société privée SCNCT (Société cotonnière du Nord-Cameroun et du Tchad), installée à Pitoa (1934-1939) ${ }^{11}$, «la production rationnelle du coton» ne pouvait reposer que sur des variétés de types Allen ou Triumph.

Après la Deuxième Guerre mondiale, A. Vaillant (1956), ingénieur d'agriculture coloniale, fondateur de la Station de Maroua, va essayer de codifier la culture du coton (variétés annuelles) préconisant les premières méthodes et façons culturales ${ }^{12}$. Le "champ collectif indigène " s'impose pour mieux contrôler un itinéraire technique complexe, avec les charrues de la Société de Prévoyance. Il sera sous le contrôle des chefs de canton, avec le risque de voir cette culture confisquée par ces mêmes autorités. Les chefs de Subdivision bouderont ou soutiendront très mollement ce «projet cotonnier».

On va s'inspirer des services agronomiques donnés comme plus avancés que ceux des colonies françaises et qui travaillent sur des variétés annuelles non locales : les Belges au Congo avec la Triumph big boll et les Anglais au Nigeria avec Allen. Le développement, dès après guerre et dans les années 1950, a commencé à prendre le mode d'intervention qu'on lui connaît : travailler sur des standards et effectuer des transferts. Il faut d'ores et déjà les mettre en pratique dans l'urgence, le développement par le coton ne peut attendre. Le cotonnier Allen déjà cultivé au Tchad par la Cotonfran sera retenu pour le nord du Cameroun.

27 Toutefois, si « conducteurs des travaux d'agriculture », puis « ingénieurs d'agriculture coloniale » s'accordent à passer de la culture du coton pérenne à celle annuelle avec des variétés importées, ils ne sont pas pour autant favorables à une spéculation cotonnière. Deux arguments seront alors constamment avancés : «On ne peut pas demander aux cultivateurs indigènes de céder son coton à raison de $0,50 \mathrm{~F}$ le $\mathrm{kg}[. .$.$] alors que sur le$ marché local le kg de coton égrené se vend $10 \mathrm{~F}$. L'exigence du coton est en outre un obstacle à sa propre expansion [...] il aurait tendance à accaparer les meilleures terres et sa culture se ferait au détriment des cultures vivrières et tout spécialement du mil » (Kieffer $1931: 5$ ).

28 Ce sera, bien sûr, sans compter sur la plasticité des agrosystèmes et l'inventivité des populations. Le développement, après 1950, des sorghos repiqués de type muskuwaari sur des vertisols jusque là incultes va libérer, pour le coton, de bonnes terres vouées aux cultures sous pluie, tout en assurant un efficace rattrapage vivrier (Boutrais 1978 : 72-73). 


\section{Chefs traditionnels et administrateurs : tous unis contre le coton}

29

L'opinion, si toutefois il est possible de parler « d'opinion » dans le nord du Cameroun des années 1950, du moins celle des chefs censés représenter «l'état d'esprit des populations » est opposée à l'introduction du coton colonial. Le Tchad constitue pour eux un contre-exemple. On se souvient de la fuite des populations tchadiennes sur la rive camerounaise du Logone et jusqu'au Nigeria lors de son introduction brutale dans la région de Bongor (1932). Da Costa, simple élève administrateur à Bongor va faire du zèle. Il impose le coton d'une manière violemment caporalisée sur des sols impropres à sa culture et qui, par la suite, seront dévolus au riz. Ce sera la période, tristement célèbre en pays masa du Tchad, dite «Dagosta $»^{13}$. Les disettes récurrentes que connurent les régions frontalières liées à un déficit vivrier induit par un excès d'emblavures de coton sont dans toutes les mémoires. On sait également que le « coton du chef » a donné lieu à des abus, sous forme de corvées supplémentaires... On est contre une imposition de ce coton comme nouvelle spéculation, l'arachide suffit.

\section{Le refus du coton colonial par les conseils de notables du nord}

Rarement un sujet - le coton - n'aura été aussi débattu au cours des conseils de notables. Ce conseil n'est pas qu'une chambre d'enregistrement présidée par le chef de Région. Les débats ne se réduisent pas à la seule assiette des impôts, aux seuls taux de capitation que doivent payer les différentes catégories d'imposables (païens de plaine, montagnards, peuls et apparentés, hommes et femmes...), mais des sujets, largement ouverts, font l'objet de discussions entre les administrateurs et les chefs du premier degré, représentants « naturels » de leurs populations.

31 Les chefs se font, dans ces assemblées, les avocats de leurs justiciables hostiles au coton colonial. Cette opposition résulte du fait que les cultivateurs sont habitués à leurs variétés de cotonniers, dont ils maîtrisent les techniques de culture et de transformation. On accepte difficilement qu'un cotonnier soit arraché après chaque récolte, c'est ce qui aurait provoqué les premiers échecs du coton administratif, comme à Tibati en 1924.

Dans le procès-verbal de la séance du conseil des notables de la Région du NordCameroun, tenue à Fort-Foureau (Kousseri) le 4 novembre 1939, le sultan Youssouf de Logone Birni explique les raisons de ce refus : «Le coton que nous cultivons ici n'a rien de commun avec le coton des sociétés cotonnières de la région de Yagoua, de Bongor, de Fianga, de Léré ou de Garoua. Notre coton est un coton du pays destiné uniquement aux besoins du pays pour les confections de nos gabacs, de nos pagnes et de nos boubous. Nos cotonniers sont des arbustes qui durent parfois dix ans [...]. Ils donnent quatre fructifications par an ». Le procès-verbal de la réunion plénière annuelle du conseil des notables de la Région du Nord-Cameroun précise parfaitement l'enjeu : « Il sera nécessaire de laisser subsister la culture de la variété indigène foulfoullo, la seule qui soit filée et tissée par l'industrie locale. Celle-ci est, en effet, d'une grande importance et d'un intérêt incontestable pour la région. Sur 600000 individus que compte la Région, 400000 sont vêtus d'étoffes tissées dans le pays et au moins 500 tonnes de coton foulfoullo sont employées actuellement pour la fabrication de ces

Revue d'ethnoécologie, 15 | 2019 
étoffes. Les essais de tissages faits avec les cotons importés n'ont pas donné satisfaction aux artisans ${ }^{14}$ ».

Dans ces conseils de notables de la Région du Nord, le lamido Yaya Dayrou (1943-1959), de Maroua, donne le ton. Personnalité incontournable pour les administrateurs, il ne cesse de vilipender le coton, se moquant au passage du lamido de Binder au Tchad, Saïdou Bakari, qu'il traite de maccu'do hottollo (= esclave du coton) car il a aidé au développement du coton colonial et a acquis au passage quelques rudiments de français.

Les récriminations des lamibe trouvent chez les chefs de subdivision un écho très favorable. Tous sont parfaitement conscients que le coton local alimente une chaîne d'activités et d'échanges qui occupe beaucoup de monde. Il alimente les marchés et entraîne à travers lui une véritable acculturation au mode de vie peul, perçu par nombre d'administrateurs comme un plus civilisationnel dans «l'apprivoisement des Kirdis [non musulmans] ». Toutefois ces mêmes administrateurs s'agacent, dans leurs rapports de tournées, de ne pas voir le coton local plus présent dans le paysage ${ }^{15}$. Il s'agit toujours de petites parcelles et il est cultivé pour des besoins précis, à quoi bon alors dégager de gros surplus?

\section{Le rapport Latour, encore un non au coton colonial}

Les administrateurs du Nord Cameroun avaient déjà pour tâche de mener de front le commandement d'une Subdivision avec les impératifs du temps: les voies de communication et les infrastructures des chefs-lieux. Ils devaient contrôler la culture des arachides et ses "points de traite" les plus importants. Ils surveillaient aussi les démariages, le recépage des cotonniers arbrisseaux tout en prodiguant des conseils pour produire plus, mais ils ne se montraient pas prêts à prendre en charge "la propagande » d'une culture cotonnière impopulaire et d'en assurer le suivi, d'autant, qu'au Tchad, comme au Cameroun, les compagnies cotonnières privées ont fait " endosser par l'administration une grande partie de leurs tâches, préférant se consacrer à l'achat et à l'usinage » (Boutrais 1984 : 673). Ils restent, de plus, traumatisés - par rapports interposés de leurs prédécesseurs, archivés dans les Subdivisions - par les périodes de disettes des années d'invasions acridiennes de 1930-1938. Ils ont toujours en charge le contrôle des stocks de mil par le biais de silos de réserve dans chaque chef-lieu et gros village. Le spectre des déséquilibres céréaliers engendrés par le coton les hante véritablement. Arbitres illusoires dans le combat que commencent à se livrer cultures vivrières et cultures commerciales, entre celles qui nourrissent et celles qui rapportent, les administrateurs coloniaux ne sauront que choisir.

Certains seraient plutôt pour un développement de la production locale et de surplus exportables grâce à de nouvelles variétés diffusées dans les zones de gossypiculture traditionnelle, comme entre Léré, Binder, Doumrou, Kaélé ou encore dans la région de Maroua. En 1945, le rapport annuel de la Région Nord fait état d'un projet de construction "d'une route du coton Garoua-Léré », qui en se prolongeant pourrait atteindre Maroua. « Malheureusement, le Caterpillar de la route du coton s'est arrêté à quelques kilomètres de Garoua et aucun crédit n'a été prévu pour l'exercice 1946 ».

Dans son rapport de tournée ${ }^{16}$ avec la mission du coton du 14 au 18 février 1950, l'adjoint du chef de Région, Latour, consigne, comme il se doit, son déroulement journalier. La mission CTUF (Compagnie des textiles de l'Union française), conduite par 
Carbon Ferrière et Dumont, débute à Rhumsiki où on lance cette année-là la «station climatique ». L'enquête se déroulera sur les thèmes suivants: place de la culture cotonnière, examen des sols et niveau de vie des populations. Pour cette première journée, la mission reconnaît que la Subdivision de Mokolo ne se montre guère propice au développement de la culture du coton. Après un passage très technique au centre de motoculture de Guétalé ${ }^{17}$ et un autre très protocolaire au chef-lieu de Région (Maroua), c'est la visite, le 16 février, de ce qui sera la future zone d'implantation de la Ctuf/ CFDT : la région de Kaélé. La population leur réserve un « accueil assez frais ", qui sera suivi «d'un accueil plus que frais du chef de canton et notables de Doumrou». Nous sommes ici à la frontière du Tchad. Le 17 février, c'est le départ de Yagoua pour Ndoukoula, où ils observent le "même accueil des chefs et notables; le chef de Subdivision de Yagoua, M. Duc Dufayard, expose les difficultés auxquelles le développement de la culture cotonnière se heurtera ». Le 18 février, départ de Bongor pour Mogroum au Tchad, ici le ton change, la parole est aux défenseurs du coton. J. Martin, chef du poste administratif de Mogroum, " exposera la question cotonnière ", à partir de l'expérience tchadienne, avant la poursuite vers Fort-Lamy.

La conclusion du rapport de tournée Latour ${ }^{18}$ est nettement négative et Carbon Ferrière ne le cachera pas. Faisant allusion à cette mission, il dira: "Lors de la première prospection que j'ai effectuée dans cette région, en février 1950, avec le Professeur Dumont, tous les chefs et notables avec qui nous avions pris contact manifestaient plus que de la réticence, une véritable hostilité à l'égard du coton » (Carbon Ferrière 1951).

M. Roupsard (1987 : 326) fait mention d'un rapport annuel de 1950, de la Subdivision de Kaélé19 ${ }^{19}$ l'année même où l'on va imposer le coton :

«Il est question d'essayer de donner un essor à cette culture dans les années à venir, mais l'indigène y est peu favorable et il serait très imprudent de se lancer dans une grande extension de la culture cotonnière, celle-ci risquant de nuire aux cultures vivrières et d'apporter la famine dans le pays (n'oublions pas que Kaélé ravitaille en mil le district de Léré, gros producteur cotonnier) ».

Administrateurs, chefs, notables, populations sont contre le coton. Il n'en sera pas moins imposé par décision politique et hiérarchique. Le coton en spéculation commence par un coup de force.

\section{Kaélé, capitale du coton}

41 Une poignée de personnes va imposer le coton, assurer son implantation à Kaélé et réussir son lancement sur le terrain. Ils ne sont pas moins les acteurs d'un véritable dessein économique. La France veut se donner les moyens d'intervenir en Afrique avec la création, en 1946, de l'IRCT (Institut de Recherche du Coton et des textiles exotiques) et en dégageant pour la promotion, entre autres, du coton, des fonds d'investissement (le Fides) créés la même année. Une société d'économie mixte sera mise en place en 1949 et prendra finalement le nom de CFDT (Compagnie française pour le développement des fibres textiles). La CFDT fera le choix du Nord Cameroun et Kaélé deviendra la « vitrine » de son action en Afrique française (Roupsard 1987 : 329). 


\section{L'imposition du coton par le trio Soucadaux, Carbon Ferrière et Dumont} accompagné du Pr. René Dumont (1950). R. Dumont enseignait à l'Esaat (Ecole supérieure d'application d'agriculture tropicale) à Nogent-sur-Marne. Un an plus tard il se verra confier la chaire d'agriculture comparée à "l'Agro ». R. Dumont donna son aval en estimant les possibilités du Nord-Cameroun à environ 12000 tonnes de cotongraine... Si R. Dumont écarte le coton des montagnes, il pense que la production cotonnière pourrait doubler en cas de descentes organisées des montagnards. C'est ce qui sera mis en pratique dans les décennies 1970 et 1980. La productivité du travail en faveur de l'arachide se révélant alors largement supérieure à celle du coton et le prix du coton lui-même sur le marché artisanal étant élevé, R. Dumont (1950:6) conseille d'acheter le kilo de coton-graine 50 \% au-dessus du prix d'un kilo d'arachides, condition pour lui nécessaire pour « compter développer une production cotonnière notable au Nord-Cameroun ». Ce sur-prix du coton aura comme effet d'écarter la constitution d'un groupe de commercialisation privé au profit d'une société d'économie mixte. Cette société disposerait d'un monopole de commercialisation, mais s'engagerait à acheter toute la production et à « moderniser » les techniques culturales; ce qui, par rapport à la culture cotonnière du Tchad, représenterait une démarche bien différente (Boutrais 1984 : 674). Sa mission pour la CFDT à propos du coton au Tchad et au Cameroun sera pourtant jugée comme un épiphénomène de sa carrière - à moins qu'il ne s'agisse d'un passage à esquiver car il s'agissait bien là d'une mission avalisatrice d'un projet cotonnier. Dans ses biographies (Besson 2004), on lit, en revanche, qu'il ne s'investit en Afrique et en Asie qu'après 1955. Le coton au Tchad et au Cameroun - et ailleurs - sera par la suite critiqué par le professeur R. Dumont.

«Monsieur de Carbon" - comme on l'appelait à la CFDT - se sent véritablement missionné pour apporter le coton, mais il a affaire à forte partie et il lui faut encore séduire les administrateurs, tenants du vivrier et de l'arachide et réfractaires au coton. Il souligne, avec R. Dumont, « qu'il doit y avoir place dans le Nord, et pour le coton et pour l'arachide... $»^{21}$, il n'en dénonce pas moins les aides perçues des institutions qui soutiennent l'arachide. Pour lui, il faut tendre le plus rapidement possible vers une production suffisante pour couvrir les frais d'encadrement sans aide financière extérieure. Il indique par là ce que sera la marche à suivre pour le coton dans ce qui ne 
s'appelle pas encore une filière: ne jamais s'écarter du cadre strict de l'autofinancement.

\section{Les dessous de la négociation locale}

Un conseil économique de la Région a réuni à Maroua, fin 1950, les techniciens Carbon Ferrière, Grand-Clément, Gandouat, et les grands lamibe de Mindif, Doumrou, Guirvidig... le lamido de Maroua en tête. S'y ajoutaient les chefs de subdivision sous la présidence du chef de Région Guy Georgy. L'interprétariat était assuré par le turjman Bouba Danki. L'ordre du jour portait sur la définition du lieu d'implantation de la CFDT pour lancer le coton dans le Nord.

Le lamido Yaya refusa tout net l'implantation de la CFDT à Maroua, pour lui «le coton amène la famine, l'expérience du Tchad l'a prouvé ». On penche pour rester dans une région traditionnellement productrice de coton. Maroua dit non, alors ce sera Kaélé. Depuis la mission du Commandant Lenfant (1904-1905), la région de Kaélé est remarquée pour sa production cotonnière. Dans l'annexe de l'ouvrage du Commandant Lenfant (1905 : 266-272), H. Lecomte signale l'importance de la culture du coton dans le lamidat de Binder et le pays mundang. Binder est désigné comme une "grande cité cotonnière » où le coton est une culture « d'État ». Il y expose avec beaucoup de lucidité les bases de la future culture cotonnière dans la région. Par la suite, après la Deuxième Guerre mondiale, l'autorité coloniale va porter un regard très positif sur la société mundang. Les Mundang sont désignés comme "un peuple ouvert à la modernité ", " réceptif » et " perfectible», sensible à l'action missionnaire et plus encore à l'école. On retrouve ces éloges à longueur de rapports administratifs. La combinaison de ces deux connotations va faire de Kaélé un évident centre d'accueil pour l'introduction de cette autre culture cotonnière.

Mais le gong (chef) de Kaélé, Kakiang Wappi, influencé par le lamido Yaya, se déclare contre. Le chef Zoua Waping, de Lara, se montre hésitant. Il a toujours eu une réputation de chef progressiste et, pour les administrateurs, de " premier de la classe " dans la cour des chefs. On sort alors de la salle pour des conciliabules. Dans son pick-up Chevrolet, le nouveau chef de subdivision de Kaélé, Jean Mazarguil, dit à Zoua : «On ne peut refuser, avec la CFDT, c'est le progrès et la richesse qui arrivent ». De retour à la réunion, Gong Zoua dit : " Je suis preneur ».

Une équipe est alors désignée pour le choix du meilleur site. Gong Zoua leur montre Makebi, au sud de Lara. Trop excentré en brousse il deviendra une zone d'essais, qui dans les années 2010 fonctionne toujours comme une antenne pour des essais agronomiques. Le débat sera de courte durée, l'implantation de la CFDT ne pourra être qu'à Kaélé. M. Baudelaire, ancien administrateur à Kaélé - où il a réaménagé le plan de la ville et créé son centre commercial - pressenti pour lancer sur place le coton, les a rejoints et suggère un emplacement à proximité de l'aérodrome de Kaélé fraîchement inauguré $^{22}$. Le gong de Kaélé, Wappi, n'a plus qu'à accepter ${ }^{23}$.

51 On construit en 1952 deux cases quadrangulaires, une pour M. Baudelaire, l'autre pour J. Martin et deux cases circulaires (boukarous) pour leurs bureaux respectifs. La CFDT était implantée à Kaélé. Par ailleurs, on voit se mettre en place les prémices de la filière coton en Afrique française, fortement appuyée par le pouvoir gaulliste, les administrateurs comme Mazarguil et Capelle, son successeur, étant de fervents gaullistes. 

cette époque, avec l'infatigable Carbon Ferrière, Grand-Clément (1957) installé à Tikem, et Bouba Danki, promu interprète de la CFDT, auprès de tous les chefs, à Mora, Guirvidig, Tchéboa...jusqu'à Rey. À Rey - vaste lamidat de la superficie de la Belgique le lamido est immédiatement d'accord pour imposer "son " coton. Il réclame quatre quarts (un hectare) par petit village et huit quarts et plus pour les grands. Sur cette pratique, de type féodal, « le blanc ne parle pas » et le chef de Subdivision de Tcholliré, Florès, ferma en effet les yeux. À Bibemi, le lamido, pour se démarquer de Rey et rester fidèle à ses positions anti-coton, a des velléités de le refuser dans son « commandement ». Le chef de Circonscription de Garoua, Tirant, l'en dissuade par un célèbre : « Non, Sali !» (Tirant 1954) et le lamido s'exécutera. On n'hésite pas à inviter les chefs récalcitrants à la station de Tikem (Tchad) pour leur montrer les multiples essais sur les cotonniers. encadrement général qui apparaît aujourd'hui comme très " caporalisé ». Les méthodes employées en matière de culture de rente étaient celles de leur temps et elles ne choquaient que dans leurs abus. Les cultivateurs mundang, par exemple, en font aujourd'hui deux lectures, l'une victimaire: «On chicotait trop et le coton était le prétexte de gros prélèvements de la part des chefs », et une autre, positive : «Il n'y avait pas de paresseux, on ne trichait pas sur le poids du coton » et, enfin, «C'est avec l'argent du coton que l'on s'est habillés ", "c'est avec lui que l'on a pu envoyer nos enfants à l'école» (Seignobos 1998 : 31). Les manquements envers l'itinéraire cultural furent, au début, sanctionnés, comme en attestent des dizaines de procès-verbaux (Archives de la sous-préfecture de Kaélé, 1954-1956), principalement à l'encontre de ceux qui n'arrachaient et ne brûlaient pas les cotonniers après la récolte. Pour une infraction à la réglementation de la culture du coton (arrêté 5782 du 12 novembre 1952, art. 6 et 7), il pouvait en coûter une amende de $500 \mathrm{~F}$.

\section{Deux anciens administrateurs coloniaux comme équipe de lancement : J. Martin et M. Baudelaire}

composition de la première équipe de terrain rend encore compte du choix de Carbon Ferrière. Jacques Martin, chef de district au Tchad était sorti de l'École d'agronomie tropicale de Nogent et « connaît admirablement les problèmes techniques de la culture cotonnière de ces régions " (Carbon Ferrière 1951). Il parle l'arabe et le fulfulde, sa femme est une Peule. Il en impose aux populations par sa connaissance des hommes et du milieu. J. Martin se livre aux premiers essais sur 830 hectares, les graines viennent du Tchad, de Mombaroua et de Tikem. Il se dépense sans compter pour s'assurer que semis, démariages, sarclages ont été correctement menés et dans les temps. Le fameux itinéraire technique Sodecoton vit ses premières applications, usant déjà des primes en conséquence. Pour les 2500 cultivateurs mis sur fiches, il a noté la nature des sols de leurs parcelles d'après les noms vernaculaires.

Les administrateurs coloniaux qui s'étaient exercés à la pratique du fulfulde ont quasiment tous, dans les rapports de tournée, signalé les grands types de sols dans cette langue et leur adéquation avec les cultures et les rotations culturales. Dans les années 1950, la pédologie s'affichait comme la discipline maîtresse du développement. C'est elle qui avalise les projets et sera sollicitée pour cela jusqu'au tout début des

Revue d'ethnoécologie, 15 | 2019 
années 1980. C'est l'époque des grandes prospections et inventaires des sols, de leurs pédogénèses avec Martin et Pias, pédologues à l'Orstom (Bachelier \& Pias 1952).

Les efforts de J. Martin vont aboutir. Le premier marché de coton fait entrer 450 tonnes pour une prévision initiale de 60 à 80 tonnes. Le rendement des parcelles près des habitations (il n'y a, bien sûr, encore aucun intrant) se situe entre 650 et $900 \mathrm{~kg}$ de coton-graine $\mathrm{e}^{24}$. J. Martin devait, par la suite, ouvrir tous les postes difficiles du coton, comme à Touboro en 1954-1955, chez le lamido de Rey. À Lara-Makebi, il expérimentera, pour le coton, la formule de l'époque: le "paysannat», un encadrement rapproché des paysans ${ }^{25}$. Au sein de chaque paysannat cotonnier, on créa une grande sole permettant de mieux suivre les assolements et la discipline des campagnes cotonnières. Cette sole devait définitivement transformer le parcellaire des terroirs villageois. On imagine encore mal ce que cette intrusion a pu entraîner comme perturbations pour les communautés villageoises, non plus que le poids de cette contrainte. On abandonna rapidement la formule du paysannat pour passer à une organisation très hiérarchisée d'encadreurs-surveillants depuis le «boy-coton » jusqu'au chef de zone, puis de région.

Maurice Henri Baudelaire qui passe pour un fin connaisseur des populations locales, des Peuls en particulier, est, aux dires des intéressés l'un des rares administrateurs à avoir percé le faasikaare (l'hypocrisie, la duplicité) des lamibe grâce à sa connaissance $\mathrm{du}$ fulfulde. Ses rapports administratifs en sont la preuve. Ce fut l'un des administrateurs qui demeura le plus longtemps dans le nord du Cameroun ${ }^{26}$. Des pièces de monnaie portent même son nom, siisiyel bodorel, suleyre bodorel... (Seignobos \& Tourneux 2002 : 291). Comme J. Martin, il n'a nul besoin d'interprètes. Sa femme est une Peule de Doumrou. Appelé «nebbam biriiji» (huile d'arachide) pour s'être illustré dans la traite des arachides, il deviendra «nasaara hottollo», le «blanc du coton». Ses démêlés avec certains lamibe, ceux de Bibemi et de Mayo Loué, ont défrayé la chronique du temps, et le lamido de Mayo Loué, dont il dépeça le commandement, se serait - dit-on - déplacé à Kaélé pour le voir et constater la déchéance d'un commandant devenu « boy-coton ».

M. Baudelaire, détaché à la CFDT en avril 1951, devra néanmoins «recevoir des conseils" à l'IRCT de Tikem, au Tchad, auprès des autorités administratives, des services de l'Agriculture et des pédologues de l'Orstom basés également à Tikem. La CFDT accordera, pour mieux appuyer son action, une prime à l'ensemencement de $1800 \mathrm{~F}$. par hectare, soit 4,5 F de coton-graine. Il s'agit de payer à l'avance une partie du prix de la récolte afin d'encourager le paysan. Cette prime aura un effet déterminant sur le lancement de la culture d'autant qu'à cette période, le paysan est à court de trésorerie. Le maintien de cette pratique fera la force de la CFDT qui dispose ainsi d'une garantie de recouvrement des échéances sur les marchés de coton. Dès leurs débuts ces marchés ont été suivis et approvisionnés par des « commerçants forains qui déballaient leurs marchandises à même le sol sur de grandes bâches » comme le signale Maurice Delauney $(1986: 55,56)$, administrateur à Yagoua et qui a imposé la « corde » unité de mesure obligatoire de coton à cultiver. Par la suite, l'administration trouvera commode d'y relever l'impôt et de délivrer là les tickets d'acquittement. La CFDT pourra faire passer toutes les innovations techniques du développement, si bien qu'elle l'emportera systématiquement sur les services, concurrents, de l'Agriculture.

Ces administrateurs, devaient insuffler une façon de travailler au plus près des populations, méthodes que continueront à appliquer les chefs de zones, de secteurs et 
de régions de la Sodecoton, expatriés, puis nationaux, à pied, à mobylette, moto, pickup...Ils devaient aussi influencer l'encadrement de la CFDT sur le terrain, qui va se calquer sur le découpage administratif. Le secteur correspond à la subdivision et le chef de secteur est l'animateur et le vulgarisateur, associé aux chefs de canton. En 1955, on compte une dizaine de secteurs. Celui de Kaélé joue un rôle pilote dans la vulgarisation avec le « sous-secteur de modernisation » de Lara (1954). La culture attelée connaîtra là ses vrais débuts (Seignobos \& Iyebi-Mandjek 2000).

La machine CFDT fonctionne avec la caution gouvernementale, et, sur le terrain, les représentants de l'autorité publique sont souvent appelés à se mettre à son service. La genèse même de l'imposition du coton en spéculation devait influer les comportements futurs de la CFDT-Sodecoton et ce sur plus d'un demi siècle : passer en force, seul et contre tous.

61 Après l'indépendance, l'interaction de l'administration territoriale et de la CFDTSodecoton va devenir plus manifeste encore, au point d'entendre des paysans dirent: «Ce que la Sodecoton veut, le Gomna (= gouvernement) le veut ».

\section{Conclusion}

La Sodecoton représente, aujourd'hui encore, la colonne vertébrale économique du nord du Cameroun et l'on ne saurait imaginer sa disparition. On peut toutefois s'interroger sur l'implantation, très directive dans les années 1950, de standards de la culture cotonnière industrielle avec des cultivars exogènes. A-t-on accordé toute l'attention voulue aux cotonniers locaux, aux techniques et façons culturales qui leur étaient dévolues? Aurait-on manqué, dans un temps où l'on se préoccupait peu de biodiversité, de procéder à une culture du cotonnier différente?

\section{BIBLIOGRAPHIE}

Bachelier G. \& Pias J. 1952 - Prospection des sols à coton dans le Nord-Cameroun. Yaoundé/Cameroun, 14 p. multig. + carte.

Besson I. 2004 - Un auteur prolifique qui estimait simplement « avoir fait son boulot » In : Un agronome d'exception René Dumont, 1904-2001, Numéro de Ingénieurs de la vie. Revue des ingénieurs de l'INAPG juillet-septembre $468: 23-27$.

Boutrais J. 1978 - Compétition foncière et développement au nord du Cameroun : la plaine de Mora. Cahier de l'ONAREST, 1 (2).

Boutrais J. 1984 - Une histoire régionale du développement rural : le nord du Cameroun. In : Cultures et développement, Univ. catho. de Louvain/Louvain-la-Neuve : 655-700.

Carbon Ferrière J. de 1951 - Rapport d'activité de la compagnie française pour le développement des fibres textiles au cours de l'année 1951, 91 p. (Chap. III Nord Cameroun : 36-46).

Chevalier A. 1907 - L'Afrique centrale française. Paris, Challamel, 778 p. 
Delauney M. 1986 - Kala-Kala, De la grande à la petite histoire. Un ambassadeur raconte. Paris, Robert Laffont, $319 \mathrm{p}$.

Dumont R. 1950 - Les possibilités cotonnières du nord Cameroun (régions du Nord-Cameroun et de la Bénoué), 7 p., note In : Les possibilités d'accroissement de la production cotonnière en AEF : Oubangui et Tchad. 43 p. + notes annexes.

Georgy G. 1992 - Le petit soldat de l'Empire. Paris, Flammarion, 271 p.

Grand-Clément M. 1957 - Secteur de modernisation de Lara. In : Les capitaux autochtones et leur mobilisation dans l'économie rurale, III symposium international d'économie rurale tropicale. Paris, 1956. Min. Fr. d'Outre-Mer. Orstom : 196-205.

Heim de Balzac F. 1930 - État actuel de la culture cotonnière dans les Possessions Françaises de l'Afrique Noire, Tchad, Cameroun et Oubangui-Chari. In : Coton et culture cotonnière, 5, (1) : 3-15. Hutchinson J.-B. 1949 - The dissemination of cotton in Africa. Emp. Cott. Grow. Rev. 26 (4) : 256-270.

Kieffer C. 1931 - Conducteur de travaux d'agriculture, «A Monsieur le chef de circonscription de Maroua », Rapport annuel 1930, Maroua, 13 p.

Lamb V. et Lamb A. 1981 - Au Cameroun weaving-tissage. Cameroun, ELF Serepca, 192 p.

Lenfant Cdt. 1905 - La Grande route du Tchad. Paris, Hachette, 285 p.

Malzy P. 1954 - Quelques plantes du Nord Cameroun et leurs utilisations. JATBA, 1 (7-9) : 148-179. Roupsard M. 1987 - Nord-Cameroun, ouverture et développement d'une région enclavée. Thèse doct., Paris X, $516 \mathrm{p}$.

Seignobos C. \& Schwendiman J. 1991 - Les cotonniers traditionnels du Cameroun. Coton et fibres tropicales, 46 (4) : 309-322.

Seignobos C. 1998 - Le pays mundang, du « Progrès » au « Développement durable ». Minagri/ Sodecoton/IRD, DPGT, $123 \mathrm{p}$.

Seignobos C. \& Iyebi-Mandjek O. 2000 - Atlas de la Province Extrême-Nord, Cameroun. Paris, IRDMinrest-INC, $172 \mathrm{p}$.

Seignobos C. \& Tourneux H. 2002 - Le Nord-Cameroun à travers ses mots. Dictionnaire des termes anciens et modernes. Paris, IRD/Karthala, $334 \mathrm{p}$.

Shimada Y. 1992 - Formation de la civilisation « complexe », Islam et vêtements en Afrique subsaharienne : étude de cas de l'Adamawa. In : Shohei Wada \& Paul K. Eguchi Ed. Africa Senri Ethnological Studies 4 (31) : 373-422.

Tirant R. 1954 - Compte-rendu de la réunion tenue à Garoua le 27 janvier 1954 à l'occasion du passage de M. Rossin, Directeur de l'Agriculture, de l'Elevage et des Forêts au Ministère de la France d'Outre-Mer. Archives de Garoua, 19 p.

Tournée de l'administrateur Latour, adjoint du chef de Région avec la mission du coton, du 14 au 18 janvier 1950. 2 p.

Tourneux H. \& Seignobos C. 1997 - Origine et structure du lexique botanique peul du Diamaré In : Barreteau D., Dognin R. \& Von Graffenried C. Ed. L'homme et le milieu végétal dans le bassin du lac Tchad. Paris, Ed. Orstom : 195-216.

Vaillant A. 1956 - Contribution à l'étude agricole du Diamaré (Nord-Cameroun). L'agronomie Tropicale 11 (4) : 448-476. 


\section{NOTES}

1. Sodecoton : Société de Développement du Coton du Cameroun qui prend, en 1974, la relève de la CFDT (Compagnie Française pour le Développement des fibres Textiles).

2. Allen est une variété améliorée (1880) nord-américaine, de l'espèce "Upland" G. hirsutum, introduite au Nigeria au début $\mathrm{du} \mathrm{xx}^{\mathrm{e}}$ siècle. Allen a été utilisé lors du développement de la culture cotonnière en Afrique francophone après la seconde guerre mondiale.

3. Tous les termes sont en langue peule du Diamaré, également langue véhiculaire : le fulfulde.

4. Les anthocyanes sont les pigments rouges situés dans les vacuoles des cellules des feuilles.

5. Nos enquêtes régionales nous ont permis de confirmer les grandes lignes de diffusion des cotonniers telles que signalées par A. Chevalier (1907) et développées par J.-B Hutchinson (1949).

6. À la façon de "sultanat", "Lamidat" dérive du mot "lamido" (du peul laamii'do, pl. laamii'be), chef, et désigne le territoire sur lequel s'exerce la juridiction d'un lamido.

7. P. Malzy, 1954 : 167, signale « un Gossypium sp. (lihere manakatié), cotonnier de variété Allen importé par les Européens ».

8. Gatau R., chef de Subdivision de Fort-Foureau, 6 novembre 1939, in Rapport de Tournée dans le sultanat de Goulfei: "Dans les villages où il y a des Bornouans, on trouve du coton, objet de transactions intérieures sur les marchés, mais uniquement destiné au tissage des bandes de gabak. On trouve aussi de l'indigo ». Ces propos pouvaient être étendus à toute la région du Diamaré, plus au sud.

9. Dans un extrait du rapport du Cpt Meyer, Rapport de Tournée du 25 au 30 juin 1918 dans les Régions des Kirdis du Mandara, Archives de la sous-préfecture de Guider, 8 p., on peut lire, page $3:$ « [...] le Kirdi qui ne pourra pas payer son impôt avec de l'argent, car bien entendu il est rare chez les indigènes, puisqu'ils n'ont aucune relation avec l'extérieur, le payera avec des bandes de toile. Cette marchandise trouvera toujours des acquéreurs chez les Foulbés et les Haoussas. Un bon rouleau se vend de 2 à 3 francs et même 4 francs ".

10. Les montagnards mofu et mafa gardent une sorte de dee'do (peau lombaire en fulfulde), mais ils adoptent aussi le godon, pièce de tissu dont ils se drapent un peu à la façon d'un peplum durant les décennies 1960 et 1970. Les femmes s'entourent la taille d'un petit pagne de godon (gudel) pour se rendre sur les marchés.

11. Son arrêt en 1940 sanctionnait à la fois l'échec de tentatives de plantations capitalistes et celui de paysannats non encadrés.

12. A. Vaillant, « Notes sur la culture du coton ». Maroua, 16 mai 1945, A.M./35. 4 p.

13. À Fort-Lamy le gouvernorat en fit une tout autre lecture en 1933 , lors de la préparation de la campagne cotonnière suivante: «(...) les efforts de M. Da Costa ont été couronnés d'un succès inespéré [...] le résultat n'a pu être obtenu que par la présence et la mobilité du chef de subdivision qui, dans la plupart des cas, a dû faire exécuter le travail en sa présence », (Archives N’Djamena/registre économique, 1933-1934).

14. Rapport dactylographié du 11 décembre 1939, p. 6 (Archiv Prov. de Maroua, C1939 III 31, p. 7.). Le jugement énoncé semble être un a priori puisque les tisserands utilisent aujourd'hui ces mêmes métiers à tisser (pays giziga) pour travailler le coton de la Sodecoton.

15. Par exemple, J. Cédile, Tournée du 14 au 21 octobre 1939 dans l'ouest et le nord de la Subdivision de Maroua : «Partout des mils très inégaux [...]. La récolte sera juste moyenne. Les arachides que l'on commence à arracher sont belles. Le coton, rare, rare... paraît bien plus beau que les autres années ».

16. R.T. qui a fait l'objet du rapport $n^{\circ} 78$, du 28 février 1950, à Monsieur le Haut Commissaire de la République.

17. La station de Guétalé, dans la plaine de Koza, sur les piémonts des monts Mandara, couvre 700 ha aménagés avec des brise-vent. Lancée en 1948, elle teste une culture motorisée qui se révélera rapidement inadaptée. Elle sera reconvertie en centre de multiplication des semences. 
18. R.T. qui a fait l'objet du rapport $n^{\circ} 78$, du 28 février 1950, à Monsieur le Haut Commissaire de la République.

19. Archives Nationales Yaoundé/APA 11748.

20. André Soucadaux sera haut commissaire de 1949 à 1954. Il confiera à G. Georgy en 1951 la Région de Maroua. G. Georgy (1992: 145), décrit le gouverneur général Soucadaux comme « [...] un homme d'expérience et de terrain [...] mais ses directives ressemblaient à la programmation des douze travaux d'Hercule. Il convenait, disait-il d'aménager les rives du fleuve Logone pour y promouvoir la riziculture, de développer les cultures du coton et de l'arachide, de multiplier les secteurs expérimentaux et de formation agricole et de créer de toutes pièces des centres ruraux équipés d'une école, d'un dispensaire, d'une station vétérinaire et d'un marché [...] ».

21. Communications orales (2003) de l'honorable Bouba Danki, Maroua, principal interprète de toutes les transactions sur le coton et qui sera par la suite le député inamovible de la région de Bogo (1973-2002), membre du comité central de l'Unc, puis, après 1985, du Rdpc, le parti gouvernemental. J'ai travaillé de longues années avec Bouba sur le rôle des interprètes de la période coloniale

22. C'est l'époque où l'on croit à l'avion. On crée de petits aérodromes partout. Outre à expédier les carcasses des gros et petits ruminants dans les villes du sud et jusqu'à Brazzaville, l'aérodrome servira, à la direction de la CFDT, en particulier sous le long magistère de A. Dufour, lui-même pilote, pour surveiller l'évolution des emblavures cotonnières et à rallier les points les plus éloignés, comme Touboro, du « domaine cotonnier ».

23. Communications orales (2003) de l'honorable Bouba Danki.

24. En 1953 la production sera de 5330 tonnes de coton brut, avec un agent d'encadrement expatrié pour 1000 tonnes.

25. Les "paysannats» se sont développés dans le cadre du SEMnord (Secteur Expérimental de Modernisation du Nord-Cameroun) inspirés des directives de M. Rossin, directeur de l'Agriculture, de l'Élevage et des Forêts au Ministère de la France d'Outre-Mer (1953).

26. Il fut chef de la Subdivision de Garoua (1934-1937), adjoint au chef de Région de la Bénoué (1938-1939), chef de la Subdivision de Guider (1939-1941) et premier civil à ce poste. Il revient, après la guerre, comme chef de Subdivision de Guider (1944-1946), puis de Kaélé (1946-1949) et, enfin, de Tignère, en 1950.

\section{RÉSUMÉS}

Pays sous mandat de la Société des Nations (SDN) le Cameroun a échappé au coton colonial. La région du nord a pu ainsi prolonger un très actif artisanat de tissage fondé sur une gamme de cotonniers locaux cultivés en pérenne. Avertie des excès et des dérives de la culture du coton imposée dans les années 1930 au Tchad, l'administration coloniale du Cameroun dans son ensemble est opposée à son introduction sur son territoire. Elle se fait en cela l'écho des chefs locaux qui, eux-mêmes, relaient les craintes de leurs populations.

Pourtant en 1950, contre l'avis de tous, le Haut Commissaire de la République française, nouvellement nommé au Cameroun, va prôner le coton comme la seule spéculation capable de faire sortir le nord du pays de son retard économique. Sa réussite tient à l'équipe mise en place par le responsable de la CFDT (Compagnie française pour le développement des fibres textiles). Cette genèse, fruit de l'interventionnisme de l'État, devait marquer par la suite les pratiques de la société cotonnière CFDT-Sodecoton. 
As a country under mandate from the League of Nations, Cameroun first didn't have to participate in the development of colonial cotton production. The northern part of the country continued to sustain a very lively weaving craft, using an array of local cotton species and perennial cultivations. Witnessing the excesses perpetuated in Tchad along the forced introduction of cotton in the 1930's, the colonial administration in Cameroun opposed its arrival on its territory. In this regard, it echoed the many suspicions raised by local chiefs and their communities.

Nonetheless, against everyone's judgement, the newly appointed High Commissioner of the French Republic in Cameroun started promoting colonial cotton in 1950, as the only commercial item able to raise North Cameroun out of economic underdevelopment. Its success resided in the creation of a dedicated team of experts, led by the director of the Cfdt, the Compagnie Française pour le Développement des Fibres Textiles (French Company for the Development of Textile Fibres). The inception of colonial cotton production in Cameroun shows the extent of state interventionism and greatly influenced the business model of the African cotton industry, dominated by the ever-powerful cfdt-Sodecoton.

\section{INDEX}

Mots-clés : Nord Cameroun, coton traditionnel, coton colonial, basse époque coloniale Keywords : North Cameroun, traditional cotton, colonial cotton, "Late Colonial Period"

\section{AUTEUR \\ CHRISTIAN SEIGNOBOS}

Géographe, chercheur IRD (Institut de Recherche pour le Développement - Adresse postale : 2 rue des Dominicains. 13200 ARLES - christian.seignobos@wanadoo.fr 